\title{
La Poesía de Jaime Torres Bodet
}

Dentro de la tradición larga y honrosa de los poetas que se han dedicado al servicio de su país, entre los que mayor prestigio han alcanzado figura el nombre de Jaime Torres Bodet. La suya es una vida de servicio tanto a su pueblo como a los otros pueblos del mundo. Conocidísima es su actuación como Jefe del Departamento de Bibliotecas, Secretario de Educación y, más tarde, de Relaciones Exteriores, Director General de UNESCO y Embajador de México a la República Francesa. Se le ha colmado de honores: Miembro del Colegio Nacional en su país natal, se le ha conferido el grado más alto de la Legión d'Honneur, ingresó en la Academia Francesa de Bellas Artes, siendo el primer hispanoamericano a quien se le confiriera tal honor, y le otorgó el Prix des Amitiés Françaises la Société des Poètes Français.

Pero - debido quizá a la innegable calidad de sus trabajos no literarios- que sepamos, no ha gozado del aprecio que merece como poeta. Se le ha elogiado en términos calurosos, pero raras veces se reconoce, como debe reconocerse, que su poesía de los últimos años es tan intenso homenaje a la dignidad humana como su labor de educador y funcionario. Nuestro propósito es el de trazar ciertas particularidades de su obra poética, con la íntima seguridad de que, si para el mundo Torres Bodet es funcionario, para sí mismo, para adentro, es poeta.

\section{EL ESCRITOR Y LA LIBERTAD}

Antes de penetrar en su obra, debemos recalcar algunas notas importantísimas respecto de ella, publicadas hace poco por el mismo Torres Bodet. Además de proporcionarnos el pensamiento de un distinguido autor sobre problemas graves iluminan su obra madura. Aludimos a Tiempo de arena y al prólogo a Tres inventores de realidad, en los que se desarrolla 
un concepto serio y meditado de los derechos y los deberes del escritor. El deber primario es el de escoger entre las múltiples expresiones posibles, la que mejor corresponda a las necesidades anímicas del escritor, la que mejor cuaje lo que tenga que decir. "El mundo brinda al artista no, como al sabio, una serie de verdades por descubrir y por explicar, sino una serie de formas entre las cuales ha de elegir. Y entre las cuales ha de elegir una solamente: la que es más suya, la que ningún otro patentaría con mayor autoridad y mayor derecho que él". (Tres inventores de realidad, Io) Derecho de escoger, de ser consecuente consigo mismo, y de no traicionar, ni a la humanidad ni a sí mismo, porque es imprescindible que la forma escogida, plasmada, sea "útil", clara, congruente, emancipadora". $(O b$. cit. II) Y que no se despiste el lector; lo de útil nada tiene que ver con la practicalidad ni con el pragmatismo, y lo de emancipador lejos está de la mera política. Porque el significado profundamente humano de esta pocsía de Torres Bodet va mucho más allá del momento: penetra en el corazón vivo y sangrante del hombre. El que respira hoy, el que respiraba ayer, el que respirará mañana, todos son nuestros hermanos y todos estamos mutuamente complicados irremisiblemente - porque somos hombres.

"La libertad es un derecho de opción, entre dos o más posibilidades" (Ob. cit., I4). Por consiguiente, el escritor que no tenga este derecho, cualesquiera que sean las razones, no es libre. "El que escoge afirma su libertad." (Tiempo de Arena, 107) Pero esta libertad dista mucho del jadeante empeño de escribir lo que se está escribiendo en París. "La libertad no es un desahogo de caprichos, sino un equilibrio de obligaciones." (Ob. cit., r98-9) "...en el mundo del arte no hay libertad exterior sin rigor interno." (Educación y concordia internacional, 519) Cuando escoge el artista, nada más elige el camino; todavía le espera el viaje, cargado de obstáculos por vencer, "...el obstáculo, trampolín de la inteligencia..." (Ob. cit., I99). Si el camino carece de obstáculos, no es legítimo. Somos hombres y participamos igualmente en la profunda, inexpresable tristeza de ser hombre. El mundo no se divide en dos mitades opuestas, sino que todo ser forma parte de la totalidad. Si el escritor busca la belleza, tiene que encararse con el llanto, porque "... no hay belleza que no sea trágica..." (Ob. cit., 213).

\section{LOS PRIMEROS LIBROS}

Nacido en I902, a los I6 años Torres Bodet se lanza a la imprenta con Fervor. A los 24 años, tenía ya sus nueve títulos publicados, si inclui- 
mos el libro antológico Poesias. Tal fertilidad en poeta de tan tierna edad fatalmente acarrea una nutrida cantidad de mala poesía, y no se salva Torres Bodet. Excelentes poemas hay, pero escasean. Y sin embargo, en estos ensayos se esbozan temas que marcan preocupaciones constantes, cuya expresión no se logra hasta la madurez del poeta. Predomina el tema de la búsqueda; el poeta se halla desvinculado de su ambiente, ansioso de echar raíces sin poder. De ahí arranca la nostalgia del campo tan característica de los primeros libros, de ahí surgen los versos desiguales de "El poema de la urbe cruel."

Se hace patente el problema capital en "Vida" (Los dias) cuando protesta el escritor contra la rutina, cuando le espanta el temor a no ser ya "...más que un pedazo de la máquina."

El alma, sí. Me acuerdo ahora...

No sé ya dónde la dejé. Sin duda

me estorbaba, para ir entre las cosas.

Dos palabras claves: alma y cosa. El poeta es alma y todo lo que le circunda es "cosa", le es ajeno, le amenaza. La vida no tiene finalidad, y el poeta - "viajero perdido" - la busca en un concepto sentimentalizado del hombre común.

¡Ser un pedazo de la muchedumbre

Que trabaja, que sufre y que vuelve a su casa!

(Tarde, Los días)

Reconoce su condición de desarraigado, e intenta comulgar con la humanidad.

Nada vale en mí mismo

antes de darlo a quien de mí lo espera.

(El don, Poemas)

Pero la comunión no se logra, y se asoma la resignación ante el ideal inal. canzable.

Vivir, porque la vida no puede renunciarse, pero hacer el menor

ruido posible.

(Adolescencia, Poemas) 
Insistimos en que en esta poesía, a pesar de sus altibajos, se dibujan los contornos que años después se plasmaron en Sonetos y Fronteras. Los versos citados contienen la semilla del magnífico sentimiento de fraternidad y dignidad que el poeta maduro supo verter en el molde purificado de su técnica.

\section{DESTIERRO: INTERMEDIO SOMBRÍO}

Así calificó Manuel Toussaint este libro tan distinto de los anteriores. Conquistado por el imán de las experimentaciones vanguardistas, abandona Torres Bodet la sencillez para hurgar en las osadías de los "ismos". Uno de los rasgos de esta época en la trayectoria de nuestro poeta es la mecanización del mundo. Se ha transformado en máquina, presidida de "¿Qué metálico Dios. ..?" (Despertador); se encuentra amenazada por la oxidación. La enfermera es "Virgen de los Termómetros" (Sueño del Hospital) y es tal la mecanización que uno puede morirse.

...súbitamente, víctima de un error simultáneo de los termómetros. .

(Biografía, II)

Este tono de burla se intensifica hasta producir una especie de grotesco en el cual se subraya la falta de sentido de la existencia La poesía no es más que

Un cambio de postura en el sueño de esa princesa que dormirá todavía mil años en el castillo de un fonógrafo descompuesto...

\section{(Abecedario E)}

Bella durmiente sin príncipe que la despierte, habitante sin esperanza de una tierra que "... está pendiente del capricho de un jugador de billar..." (Salmo, I) El universo está regido por la casualidad, y se puede interrumpir, sin razón alguna, ". . .en la penúltima sílaba de una lectura por radio". (Biografía, I) Causalidad funesta, divorciada de la casualidad, consecuencia lógica de la falta de sentido. Ya no llora el poeta acongojado ante el espectáculo de la juventud que mientras más se busca, más se aleja; rige estas páginas el espectro de un rey muerto, hermano gemelo del Rey Pescador de Eliot, pero aún más conmovedor, porque siguen sus súbdi- 
tos esperando las órdenes que jamás se darán. Caos sin forma, burla sin risa, negación total:

Se oyen pisadas que no se acercan, testigos

que no declaran, tambores que no redoblan, cornetas

en que el ejército aguarda la orden de un emperador fusilado.

(Invierno)

.. .se oye el gemido de la puerta de plata que cierra

un arzobispo demente sobre una iglesia de llamas.

(Abecedario D)

Perdido en la más espantosa soledad, el poeta continúa persiguiéndose a sí mismo, buscando su propio ser y su propia expresión, a las que se agrega otra dimensión: razón de ser, no del poeta, sino del universo. Si abandona la sencillez, es porque sabe que allí no se encontrará; el pavor ante la nada no se amolda al lenguaje trillado que ayer lamentaba la juven. tud zozobrada, o elogiaba las virtudes caseras. Habrá que divorciar las palabras de la materia para construir de nuevo el lenguaje. Destierro no es un libro logrado, a pesar de su indudable superioridad respecto de los libros anteriores. Libro de transición, de exageraciones necesarias para deshacerse de la expresión gastada ya, para forjar la nueva y propia.

\section{CRIPTA: ENCUENTRO CON IA NADA}

Tras siete años de silencio, en 1937 publicó Torres Bodet el libro que le aseguró un puesto entre los más distinguidos poetas de América. ¡Qué distinta esta lentitud del apremio juvenil! Cripta representa una purificación del lenguaje, punto ascendente en la constante búsqueda de su palabra tan característica de Torres Bodet. Ya no se siente desterrado, porque aun en el destierro pudo encontrar al semejante; más agobiador es este sumergirse en la cripta de la más absoluta soledad. La vida sigue siendo un absurdo, pero bajo la superficie yace la nada. Inútilmente intenta el poeta descifrar el misterio del destino.

Una justicia extraña-o, tal vez, sólo una máquina terca y sin justicia...

(Destino) 
El nombre

del puerto, nunca visto, donde una mano, entre gaviotas, blanca señala - nave o sueño- tu destino.

(Resaca)

Y vuelve a aparecer el tema del rey muerto.

$$
\begin{aligned}
& \text { Esas fortalezas } \\
& \text { en cuyas viejas torres } \\
& \text { un atabal redobla } \\
& \text { inexorablemente } \\
& \text { por las estrellas muertas } \\
& \text { de un pabellón caído }
\end{aligned}
$$

(Ciudad)

Esta visión de pesadilla ve el instante de felicidad como ". . égloga interpolada/en la nocturna prosa que recorre/con ojos evasivos/-como un inútil pliego sin erratas-/un corrector de pruebas sin sentido..." (Dicha)

La nostalgia de antaño se sustituye por la preocupación del tiempo, tan vinculada en la poesía hispánica con la muerte (y por algo lleva Cripta un lema de Quevedo). Pero en Torres Bodet no es el tiempo un elemento corroedor, sino enredadera que nos estrangula. O, más bien, se expresa en términos de movimiento ineludible. "Andenes son las horas en que nos reunimos..." (Andenes), igual a Abril, cuyos andenes "... nadie conoce..." (Abril) El tiempo es movimiento, progresión inexorable; repetidamente se expresa como los peldaños de una escalera cuya destinación nos está vedada. El tiempo es "... una escalera rápida que nadie/podrá jamás decir si baja o sube." (Soledad)

Tras una pucrta estoy, estuve, estaré siempre.

Tras la delgada puerta de esta mansión callada a la que el mar quería ya devoratle -- ¿cuándo?peldaño por peldaño todos los escalones. . 
. ffrente al cadáver brusco

de la mujer que un día

oí, del otro lado

de la cerrada puerta, rodar por los peldaños

de una escalera oscura...

(Fidelidad)

La mujer se vuelve símbolo de la imposibilidad de la comunión ansiada, se caracteriza por "...los fríos/peldaños que conducen/al centro de tu alma..." (Sitio) El amor sirve de pretexto para proseguir el tema de la unicidad del hombre; amor es conflicto, o, a lo más, ". . descanso entre dos viajes,/tierra entre dos abismos,/apeadero en brusco/por túneles ceñido. .." (Andenes) Se le figura la mujer ". . castillo/ceñido de rencores,/ fortaleza entre riscos,/ciudad entre cañones. .", armada de todo el aparato bélico: ". . .murallas/y puentes levadizos,/barbacanas, escarpas,/corazas y albardas..." (Isla), y al darse cuenta de que no es así, el poeta queda desorientado, porque es la única verdad que conoce. No pueden entenderse; algo hay de irreconciliable que los separa, y el hombre tiene que hacer frente al ". . odio que el amor/esconde entre las manos." (Amor)

El mundo sigue siendo máquina, y hasta el añorado Abril se le ha vuelto ". . automático abril/de un año descompuesto. .." (Abril) El poeta se debate inútilmente entre las cosas que le rodean: espejos, castillos, escaleras, relojes - ". . la piqueta invisible/que remueve en nosotros/una tierra de angustia/cada vez más secreta,/para abrir una tumba/ cada vez más profunda." (Reloj) La personalidad se pierde entre múltiples manifestaciones de la mecanicidad.

Enterrado vivo

en un infinito

dédalo de espejos,

me oigo, me sigo,

me busco en el liso

muro del silencio.

Pero no me encuentro.

(Dédalo) 
Ni sabe por qué es poeta ni por qué se siente llamado a servir a este ".. Rey desesperado/que... decreta mis acciones..." (Poesía) Incapaz de comprender, sin poder ser distinto, clama impotente.

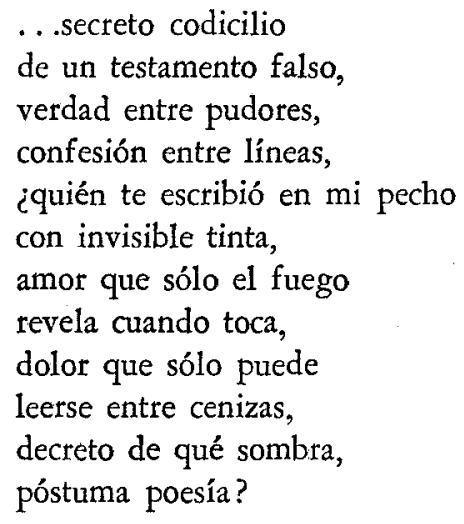

(Poesía)

SONETOS: LA PALABRA LOGRADA

Pasaron doce años antes de publicarse Sonetos, acaso el libro más difícil de Torres Bodet. No es la dificultad rebuscada del oscurantismo preciosista ni se debe a falta de capacidad expresiva; es la dificultad de todo libro profundo, producto del intenso buscarse a sí mismo. Como si lo reconociera de antemano, el poeta desistió de la forma libre de Cripto para valerse del soneto, forma más precisa. Ni emplea el proceso de libre asociación aprendida en excursión surrealista; vuelve a la estructura predilecta de su juventud: sistemático desarrollo de una imagen básica. El resultado es un libro en el que se aproxima a los gigantes de la agonía barroca, y en especial, en la maciza piedra viva de Continuidad, al Quevedo de los sonetos.

Porque éste es libro de madurez, como lo proclama ya en "Arte poética":

Agosto endulza, inteligencia, el grano

en que el racimo al esbozarse piensa

y en gotas de ámbar lúcido condensa

el frenesí del cielo meridiano. 
Ya pasó para siempre el Abril tan llorado, y ahora el poeta arde en llamas frías de la terrible verdad: ". . invierno interior, nunca tan mío." (Lucidez) $\mathrm{Y}$ entiende, envuelto en el frio roedor de este invierno agónico:

Conforme va la vida descendiendo - bajamar de los últimos ocasosse distinguen mejor sombras y pasos sobre esta playa en que a morir aprendo.

(Bajamar)

Una vez sabido el destino, se convierte en meta que el poeta ganará cuando definitivamente deje de vivir.

$\mathrm{Y}$ en el cielo ulterior, de nuevo en calma, cuando terminen de caer las hojas miraré, al fin desnudo, mi deseo.

(Octubre)

¿Por qué inquietarme de tu cercanía, Muerte, si la existencia que me halaga es sólo pulpa de la fruta aciaga en la que yaces tú, simiente fría?

(Muerte)

En el mismo poema, puede decir Torres Bodet con Quevedo y con Rilke, que la muerte es "Llaga que de mí propio se sustenta:/úlcera primordial..." Pero la resignación no quita el horror, y pocos estremecimientos hay como éste:

...el tiempo que has vivido no fue sino un paréntesis inerte entre dos estertores sin sentido

Ya se sabe adónde nos llevan los carriles. 
Acosado ya no por la duda sino por la inevitabilidad, el poeta anhelante sigue hurgando en sus propias entrañas. Si la fe le llevaba de la mano hacia una meta que a fin de cuentas resultó inalcanzable, "... no te culpo, fe, no me has mentido:/ ibrújula te creí-y eras veleta!" (Fe) Y la voz anhelada no existe ya en este mundo; voz que se encontrará "...cuando de ver y de sentir cansado/vuelva hacia mí los ojos y el sen. tido/y en mí me encuentre..." y renazca "...en una muerte pura..." (Continuidad: IX)

Permanece inalcanzable el conocimiento de nosotros mismos porque lo único perdurable de la personalidad es su cambiar incesante. ¿Cómo podríamos encontrar nuestra verdad si esta verdad es el cambio mismo? "Muriendo y renaciendo a cada instante..." (Círculo), el hombre es el cambio personificado, petrificado por su misma velocidad, hasta que el alma se rinde y le pide a la muerte: "...jay! entra, muerte, en mí..."

...arrancándome al tedio que me acosa, envuélveme en tu vértigo, alegría, ¡afirmación total, muerte dichosa!

(Regreso IV)

Nihilismo total:

...nada es mi ser y nada mi sentido...

... sin otro epitafio que el olvido,

a la nada me erijo en monumento.

(Nocturno IV)

Claro está que esta desesperación es el resultado de la soledad angustiada de los libros anteriores. Cuando la comunión queda demostrada como irrealizable y la búsqueda de la verdad personal se encuentra imposibili. tada por la ausencia total de caracteres permanentes de dicha personalidad $-\mathrm{y}$ ambos conceptos están cabalmente expuestos tanto en Cripta como en Sonetos - no queda más resolución que abrazarse a la muerte por ser ésta la única realidad permanente.

Sólo ta muerte es tuya...

Te vivieron los otros. 
FRONTERAS: LA VUELTA AL MUNDO

En 1954, después de cinco años de lenta maduración, aparece Fronteras, libro significativamente entitulado, como todos los de Torres Bodet. Se siente ya definitivamente en la última frontera entre vida y muerte Pero de algo le han servido los años de torturada meditación, porque ahora cree haber encontrado el camino ansiado. Todavía la preocupa abril, pero está resignado a aceptar. Si el otoño le ha llegado es porque

Yo te llevaba en mí desde la hora en que más te negó la golondrina.

Peldaños que subían al otoño eran los días de mi primavera Escalera de otoño era mi prisa, y terraza de otoño mi descanso.

Por eso te acepto en todo, octubre, y te consagro, pues no eres tú quien llega de improviso sino yo quien por fin se reconoce y para ser más él se quema en ti.

(Otoño)

El destino del hombre es la muerte, y cada instante le conduce allá. Existe la posibilidad de la regenetación final, pero se le menciona sólo de paso, y primero fatalmente acontece "El día de la angustia". Para tan fatal trance el poeta pide a gritos que no le abandone la muerte que se crió.

Puertas que abrí, sobre tu enigma abrían.

Lámparas que encendi, te iluminaban.

Fuiste mi paso al caminar, mi aliento;

cuando subi, el descanso de mis cumbres, cuando bajé, la mies de mi fatiga.

Haciéndome te hice $-\mathrm{y}$ me hé quedado

de pronto sin más vida que tu ser...

El día de la prueba no me culpes.

¡No me niegues al tiempo de la angustia!

(El día de la angustia) 
Mientras tanto, existe el momento: ". . frágil puente / entre duros litorales". (Prisa.)

...tú, momento solo, minuto sin pasado, ola sin mar, primavera de un año sin octubre, tiempo desposeído

(Eternidad)

Este momento fuera del tiempo, sin vínculos con la mundana rea. lidad, linda con el instante extático de los místicos, con "... the still point of the turning world. .." de Eliot. Lo aclara Torres Bodet en los versos siguientes:

Yo vi una vez, un día solamente,

la perfección... Q Qué isla de diamante!

¿Qué insolencia de luz exasperada!

¡Qué tierras altas donde nada empieza!

El alma era, en la cumbre, como un ojo...

abierto, a pesar suyo,

sobre el paisaje brusco de lo eterno.

El tiempo

estaba suspendido

como una catarata congelada.

(El Paraíso)

Frente a la revelación, el poeta da la bienvenida regocijada al momento último.

Agradecí a mi cuerpo sus defensas:

el olvido, el cansancio, la vejez.

¡Y comprendí tu dádiva infinita.

Oh paraiso fiel, muerte segura!

(El Paraíso)

Porque en este momento suspendido, todo se le olvida, y ve la verdad que no puede expresarse. "...el artista que no persigue sino casos 
únicos y exclusivos, da de repente con la cantera misma del Universo. Al aparecer el instante, toca lo eterno". (Educación y concordia internacio. nal, II).

.. fronteras del silencio con el canto,
de la vigilia con el sueño
y de la soledad con el tumulto:
minutos
en que nada es aún y todo ha sido,
filtraciones del cielo de lo eterno,
tangencias misteriosas con un mundo
donde ya fuimos sin saber que fuimos...,
¡Principiar otra vez, ser nuevo en todo!

(Renuevo)

Pero, aún siguiendo su nueva ruta, el poeta no deja de interesarse por su más antigua preocupación: la comunión del hombre. No es él el único que sufre; si existe la comunidad, está en nuestra condición de ser hombre. Como dijo en Tiempo de arena: ". . todas las lágrimas y todos los entusiasmos de que está hecho el tesoro moral del hombre: su legado de ser mortal". (215) Si llora, es "...ese cósmico llanto que lloran todas las cosas, desde el principio de la existencia, avergonzadas acaso de haber nacido. . . la originalidad de nuestro pecado y nuestra nostalgia de un paraíso en el cual no reine sino la delicia del ya no ser". (2I6) $\mathrm{Y}$ en este legado de suf rimiento y gozo mezclado está " . . .todo mi orgullo de hombre - y también toda / la angustia que ese orgullo impone al hombre: / la dicha inexpiable..." (Mediterráneo) Sabe ya que buscar la felicidad es empresa vana, porque tal felicidad no puede ser sino muy pasajera. Feligreses del sufrimiento, los hombres no tenemos más remedio que seguir, "...unos tejiendo redes,/otros haciendo cántaros/ - hasta que un día el tiempo / no pueda ya escapar de entre esas redes, / ¡has. ta que un día el llanto de la tierra / llene por fin los cántaros!" (¿Sueño?) El hombre vive sufriendo y desviviéndose, pero en este sufrimiento se encuentra a sí mismo y a su prójimo, a su solidaridad.

El corazón tiene también palabras 
que no brotan del miedo y de la angustia, que están en él-desde la aurora eternapero que sólo se oyen en la pena.

(Estrellas)

El pecado del hombre es no cultivar esta solidaridad sino en la agonía.

Venimos de una tierra en que vivir es no escuchar las quejas de los hombres. Buscamos en nosotros y advertimos que jamás hemos dado a nadie una respuesta.

(En la aduana)

El dolor del poeta no es ya el envejecer sino el no haber tenido ". . para los hombres que de mí esperaban / una mirada de consuelo, / una palabra de confianza, / o la dádiva, al menos, / de una mano tendida honrosamente" (Solidaridad) El hombres no vive desligado de los demás; en "Continuidad" vimos que cada cual está íntimamente relacionado a su pasado personal; en "Civilización" este concepto se extiende hasta abarcar a toda la humanidad.

Un hombre muere en mí siempre que un hombre muere en cualquier lugar, asesinado por el miedo y la prisa de otros hombres.

Y su muerte deshace todo lo que pensé haber levantado en mi sobre sillares permanentes.

(Civilización)

El lector se habrå fijado ya en que estos conceptos vienen a ser como una codificación de las actitudes implícitas en toda la labor de Torres Bodet el funcionario. Pero la poesía tampoco es pasatiempo; está en todo, en todas partes, y en el poema el poeta se consume y se explica.

Porque todo poema

es un pacto de paz entre los hombres...

(Porque todo poema) 
Y en cada poema vuelve a firmarse este pacto.

... Oyeme en ella, en la noche en que soy al fin yo mismo - sin edad, sin recuerdos, sin palabraspor fin reconciliado con el niño que fuí, con el adulto que me figuro ser y con el muerto que ya en mi carne empieza a construirse. Oyeme en ella, como en ella escucho lo que jamás tu boca me dirá: esa verdad que un ser lleva consigo sin saber que la lleva y que lo alumbra por dentro, como un vaso de alabastro; esa luz que tan solo podemos contemplar cuando cerramos los ojos a la tierra, bajo el perdón inmenso de la noche...

(Diảlogo)

\section{Sin Tregua: IA Meta AlCANZAdA}

En 1957 se dio a la imprenta el libro que sigue lógicamente a los dos anteriores: Sin tregua. Persigue los mismos temas, depurándolos; sigue presidiendo la amenaza sombría de la muerte, pero ya no le tiene miedo el poeta. Lenta, sorda pero implacablemente, bajo la superficie cicatrizada, "... un enemigo hecho de mi propia substancia / me está continuamente amenazando / sin cólera y sin odio..." (El testimonio) Casi impersonal, ". . avanza sin piedad entre las horas. .." la "deslumbrante reja" del "implacable acero". (El arado) Fero el llanto seco del macizo "Continuidad" desemboca aquí en una actitud más bien de resignada curiosidad. El poeta siente ganas de dar "...el primer paso en el umbral de la nieve..."; de "... rendirse al claro, al infinito invierno..." (Invierno) $Y$ esta muerte chica, personal, se emparenta con la muerte antigua y ritual "... sobre el tronco del toble..." "... cuando llega el trance / del combate divino!" (Ultima necat) En "Resumen", este deseo se clarifica:

En cambio, este magnífico absoluto 
de lo que ya no sufre deterioros, de lo que ya no pueden modificar ni el tiempo ni el olvido, este sólido trozo de vida inalterable que es la muerte ¡cómo nos garantiza y nos demuestra en todo!

La muerte define a la vida, le confiere el significado que el ser vivo no alcanza a comprender.

El poeta anhela esta definición final, esta iluminación de la existencia, esta ". . . tosa inmarcesible y luz sincera / (que) se ganan duramente, hora tras hora". (Dedicatoria) Y sigue: "El vago abril que el tiempo nos depara / si con los días va, con ellos huye. / Pero la juventud que se construye / sobre la madurez de un alma clara / crece conforme avanza la existencia". En la clara, cruel pero justiciera luz de la madurez, se da cuenta de lo que ha ganado. Si el tiempo era de arena y "...en la arena, / las huellas duran lo que el viento quiere. .", después del suf rimiento, tras la pasión en el desierto arenal, resucita la ciudad de los recuerdos

De nuevo en piedra se condensa el polvo.

Prevaleció la vida sobre el tiempo.

Pues de cuanto viví nada fue nunca

$\tan$ mio y verdadero

como lo es, ahora, entre playas de arena,

esta blanca ciudad resucitada

porque lo quiso el viento:

el viento que a la vez hiela y abrasa,

el que alumbra y deslumbra al mismo instante,

el viento de la última justicia,

¡el viento del desierto!

(Reparación)

Se describe este proceso en "Marea": "Entre el ancla y la barca el agua crece. / Sobre el llanto invisible asciende el alma". Y sigue ascendiendo hacia la meta buscada: ". . en la frontera que divide siempre / lo blanco de lo blanco...", allí está la inconcebible claridad, ". . allí principia el mundo que yo busco: / incierto de tan próximo y tan claro..." (Amanecer) Repetidamente se subraya el valor de esta búsqueda; buscar el triun. fo es triunfar, 
$\mathrm{Y}$ comprendí que el premio mayor de la existencia no es el alba, sino el ansia del alba, el largo esfuerzo, la noche ardiente y casta, ¡el combate del hombre con el ángel sobre la cima oscura del deseo!

(Triunfo)

Este instante supremo del triunfo queda identificado reiteradamente con la muerte, cumbustión final, llama que vuelve a aparecer a través de todo el libro.

Ya solamente vivo

-como, sobre el hogar, el tronco seco-

para el instante del supremo triunfo

que, en el leño final, proclama el fuego.

Todo, en mi alma y en mi carne, ansiaba

desde la juventud ese momento

en que se cambia por la luz la vida

y por la soledad el universo...

(El hogar)

Es necesario, si no encontrar, de todos modos buscar este momento final para encontrar la personalidad propia. Subraya Torres Bodet la búsqueda de la identidad. Somos flechas disparadas por un arquero desconocido, somos cuento narrado por un narrador anónimo mientras dicho narrador "...no encuentre un buen final para su historia, / o no se canse $y$, por piedad, la olvide". (El narrador) Si no fuera porque esta búsqueda da su propio significado a la existencia, sería ésta un caos completo. Vamos con nuestra llave en el bolsillo, nuestro sombreto numerado, el miedo en el alma, que nos traicionan (Calle).

Hace ya muchos años

- ta vez desde el momento en que nacimos-

estamos ensayando inútilmente

la misma escena lenta y sin sentido. 
Nos equivocamos de palabra, de gesto, de asunto. $\mathrm{Y}$ el gran teatro de la vida se convierte en estratagema del dramaturgo ignorado.

¿No será que el autor nos dejó en blanco

los párrafos mejores, el ímpetu imprevisto:

la escena brusca, luminosa y breve

que, si queremos ser lo que pensamos,

habremos de inventar nosotros mismos?

La muerte, a pesar de ser tan personal, tan intima, está ligada a la muerte antigua ritual, como vimos ya, y en ella participamos en el tiempo de manera doble. "Vivimos sólo de creer que fuimos. / Seremos siempre póstumos". (Resumen) Es decir, la razón de ser se encuentra cuando ise ha ido ya, y el futuro está influido por el pasado. Esta interpenetración de tiempos se ve en "Río": "Algo, secretamente, se desliza / entre hoy y mañana. / Es un ayer tenaz. .." Si la muerte nos define, está condicionada dicha muerte por el pasado que fatalmente interviene en el presente que se encuentra en estado constante de desvirtualizarse, de cambiarse de potencia presente en futuro. Es un concepto muy subjetivista: "Porque el tiempo es un río que no avanza / jamás sino en nosotros, con nosotros". Pero dentro de nosotros avanza constantemente. El hombre forma parte de una cadena temporal: "Somos el solo nudo de una cuerda infinita / que nadie tejió nunca y que de nada pende". (Nudo ciego) Suspendidos en la nada, estamos irremisiblemente interrelacionados. Y sin embargo, perdidos dentro de la atroz soledad personal: ". . entre tantas sombras, estamos solos siempre". Vivimos perseguidos por recuerdos que no alcanzamos a entender, memorias falsificadas por el tiempo, pero re. cuerdos y memorias que nos acondicionan para el presente y el futuro. En este espejo doble de pertenecer sin poderlo sentir, de estar complicados sin poder enmendar nada, formamos parte de un todo, y nosotros, a nuestro turno, acondicionamos, perseguimos.

Minuto por minuto, estoy muriendo.

Pero no muero en mí; muero en el alma de quienes se preguntan si vivo todavía...

Sin ansia ni rencor, vamos muriendo

como la noche avanza,

con todo lo que un día arrebatamos 
a la inmensa eclosión de lo posible, descendiendo la vida grada a grada y en cada grada abandonando un sueño, un continente, un siglo, una esperanza: algo que no termina con nosotros pero que, sin nosotros, ya no es nada.

Bien claro en esta actitud está el deber del hombre de vivir de tal modo que confiera significado a sus acciones. No podremos en esta vida descifrar el caos, pero quedamos con la obligación de ". . seguir, seguir, seguir, sin tregua / mientras gire la hélice invisible, / ¡hasta la extremidad de lo probable, / más allá de lo falso y de lo cierto!" (Sin tregua) Este deber es, a la vez, privilegio de asumir la responsabilidad de lo que somos, de encararnos con hombría y valor con este "...mundo virtual regido por la ausencia..." En lo que pareciera una réplica a Neruda, dice: "Nunca me cansará mi oficio de hombre". (Nunca) Y remata el poema destacando nuestra única herencia que valga: "iporque de todo cuanto el hombre ha hecho / la sola herencia digna de los hombres / es el derecho de inventar su vida!" No se cansa Torres Bodet de repetir este lema fundamental: "No sé lo que pregunto ni por qué lo pregunto / pero sé que pregunto eternamente”. (¿Por qué?) Somos flechas disparadas al azar por un atquero que no conocemos.

No pretendas saber más que el arquero.

El escoge la meta, el arco, el rumbo.

Tú pasas solamente. .

Y llegar es la excusa de tu vida.

(Flecha)

Pero hay que seguir buscando, todos "... con su daga en el costado". (Calle) $Y$ hay que saber esperar, contemplando cómo cae la última hoja, sin jactancia ni miedo.

Con mayor lealtad nadie se rinde.

Nada nunca murió con más decoro. 
$Y$-hombre, después de todo-, pide humildemente el poeta que se le otorgue valor para

...imitar su adiós sereno

y dejar de su paso un dulce asombro, ¡acariciando el aire en que perece y perdonando al viento del otoño!

Huelga decir que un poeta con tal concepto del deber humano no habrá perdido su sentimiento total de confraternidad humana. Repetidamente recalca Torres Bodet el ansia de comunidad y la correspondiente carencia. "Somos islas aliadas contra el tiempo". (Islas) Somos un atchipiélago en la historia". Pero nuestro deseo de comunión se ve frustrado: ". . no hallamos nunca el mismo idioma / en el mismo lugar, el mismo día. / ¿Quisiéramos formar un continente, / sin dejar de ser islas!" Se desarrolla este tema en "El día". Viviremos en climas distintos, hablando distintos idiomas, pero buscamos ". . .algo que sea primavera siem. pre, / abril en cualquier parte, alba en cualquier idioma: / un tiempo sin fronteras, / una patria sin horas". "Soy el único náufrago de una isla invisible, / el postrer descendiente de una época, / el último habitante de una tumba". (Ahora) Pero ningún hombre realmente está solo. "Y sin embargo escucho / el corazón de un pueblo que me llama, / el grito de un hermano que me alienta. / ¡Nadie muere sin fin! ¡Nadie está solo! / $Y$, silenciosamente, $/$ con la noche caída hago una estrella". Pero mientras tanto, hay que confesar la gran vergüenza de nuestro siglo desorientado: la huida de un pueblo vencido.

Porque nada hay $\tan$ mudo como una tribu en marcha desde el amanecer hasta el exilio, a pie, a caballo, en coche, en carros de combate, en ambulancias, ejército que avanza preguntándose a cada instante si la blanca torre adivinada al pie de la colina anuncia ya la etapa: el pajar donde pueden los vencidos hallar al fin un sueño sin fronteras sobre un suelo que ayer era una patria... 
Parece referirse el poema a un suceso político entre muchos, pero no se precisan tiempo ni lugar. Mediante el empleo del pormenor dentro de un cuadro general cuyos límites no se delimitan con claridad, el poeta ha levantado el poema desde el nivel de lo fugaz hasta colocarlo en el nivel de lo eterno. No es ésta una más de las atrocidades del momento sino vivo cuadro de la migración de los vencidos de todos los tiempos, y, a la vez, biogxafía del hombre. Porque eso somos nosotros, tribu en exilio, mientras no entendamos que somos uno.

Para nuestro gusto uno de los mejores y, sin lugar a dudas, uno de los más importantes poemas de este volumen es "La noria", expresión cabal de dos temas esenciales de la obra de Torres Bodet: el tiempo y la comunidad.

He tocado los límites del tiempo.

$Y$ vuelvo del dolor como de un viaje alrededor del mundo...

Partiendo de la imagen básica de la vida como viaje en el desierto -no será atrevido sospechar aquí un eco deliberado de la estancia de Cristo en el desierto, ya que vimos la misma alusión a la pasión en el desierto en "Reparación"- el poema demuestra que el dolor del viaje tiene su premio.

¿Fue inútil ese viaje imaginario?..

Lo pienso, a veces, aunque no lo creo.

Porque la gota de piedad que moja

mi corazón sediento

y la paz que me une a los que sufren

son el premio del tiempo en el desierto.

Tras tantos años de angustiada lucha, el poeta encontró ya la paz.

Pasaron caravanas al lado de la noria

y junto de la noria durmieron los camellos.

Cargaban los camellos alforjas de diamantes.

Diamantes, con el alba, rodaban por el suelo...

Pero en ninguna alforja

vi nunca lo que tengo:

una lágrima honrada, un perdón justo, 
una piedad real frente al esfuerzo

de todos los que viven como yo

-en el sol, en la noche, bajo el cielo de hierro-

caminando sin tregua en torno de la noria

para beber, un día,

el agua lenta y dura del desierto.

Es de importancia capital que vuelva a aparecer en este poema las palabras que dan su título al libro. Tanto en la poesía como en la vida, Totres Bodet ha cultivado y sigue cultivando sin tregua los valores más esenciales de la humanidad. Como ha dicho tan acertadamente Rafael Solana, "La biografía de Torres Bodet habrá de ser, cuando se complete, una lección de entereza, de rectitud, de entrega total a ideales nunca traicionados". (Jaime Torres Bodet, Estaciones, 6, 75). Porque el artista es, por definición, delegado. "En la lenta emancipación de las tierras baldías de lo inefable, el escritor actúa como un delegado sin credenciales del mundo y de su país. Pero actúa solo. $\mathrm{Y}$ así debe actuar. Como hombre libre; libre de servir a la libertad de sus semejantes por el ejercicio de un concepto propio y particular de su ser, de su nación y de su universo". (Educación y concordia internacional, 520.)

Frank DaUster

Rutgers University, New Brunswick, New Jersey. 